\title{
EFFICIENCY AND PRODUCTIVITY GROWTH IN INDIAN BANKING
}

\author{
S. S. RAJAN \\ Email: rajansssihl@gmail.com \\ Sri Sathya Sai Institute of Higher Learning \\ Prasanthinilayam Campus \\ Anantapur District, (A.P.) \\ K. L. N. REDDY \\ Sri Sathya Sai Institute of Higher Learning \\ Prasanthinilayam Campus \\ Anantapur District, (A.P.) \\ V. N. PANDIT \\ Email: vnpandit@gmail.com \\ Sri Sathya Sai Institute of Higher Learning \\ Prasanthinilayam Campus \\ Anantapur District, (A.P.)
}

Working Paper No. 199

Centre for Development Economics

Department of Economics, Delhi School of Economics 


\title{
Efficiency and Productivity Growth in Indian Banking
}

S. S. Rajan, K. L. N. Reddy and V. Pandit ${ }^{1}$

Department of Economics

Sri Sathya Sai Institute of Higher Learning,

Prasanthinilayam Campus, Anantapur District, (A.P.), Pin. 515134.

\begin{abstract}
This paper attempts to examine technical efficiency and productivity performance of Indian scheduled commercial banks, for the period 1979-2008. We model a multiple output/multiple input technology production frontier using semiparametric estimation methods. The endogenity of multiple outputs is addressed by semi parametric estimates in part by introducing multivariate kernel estimators for the joint distribution of the multiple outputs and correlated random effects. Output is measured as the rupee value of total loans and total investments at the end of the year. The estimates provide robust inferences of the productivity and efficiency gains due to economic reforms.
\end{abstract}

Key words: Banking, Frontier efficiency, Productivity.

JEL Classification: E23, G21, D24.

\footnotetext{
${ }^{1}$ For correspondence please contact Mr. S. S Rajan, Doctoral Research Scholar, Sri Sathya Sai Institute of Higher Learning, Prasanthinilayam Campus, Anantapur District, (A.P.), Pin. 515134. Ph.: No. (08555) 287235, E - Mail: rajansssihl@gmail.com
} 


\section{Efficiency and Productivity Growth in Indian Banking}

\section{Introduction}

Indian financial services industry is dominated by the banking sector that contributes significantly to the level of economic activity, as empirically demonstrated by Jadhav and Ajit (1996). The banking structure in India is broadly classified into public sector banks, private sector banks and foreign banks. The public sector banks continue to dominate the banking industry, in terms of lending and borrowing, and it has widely spread out branches which help greatly in pooling up of resources as well as in revenue generation for credit creation. The role of banks in accelerating economic development of the country has been increasingly recognized since the nationalization of fourteen major commercial banks in 1969 and six more in 1980. This facilitated the rapid expansion of banking in terms of its geographical reach covering rural India, in turn leading to significant growth in deposits and advances. Eventually, however, the government used banking sector to finance its own deficit by frequently increasing cash reserve ratios (CRR) and statutory liquidity ratio (SLR). This, in turn, affected the resource position of commercial banks adversely, restricting their lending and thereby the ability to generate profits. Besides, inefficiency and lack of competition caused the non-performing assets in the public sector banks to rise from 14 \% in 1969 to 35 $\%$ in 1990 . This problem had to be tackled during the nineties by undertaking an array of financial reforms.

Deregulation of the Indian financial system in 1991 followed by various financial sector reforms during the period 1990 through 1998 led to a major restructuring of the Indian banking industry ${ }^{2}$. This includes reductions in the CRR and SLR which were as high as $15 \%$ and $38.5 \%$ respectively in 1991, and preempted $53.5 \%$ of incremental deposits. These rates were reduced in a series of steps. By 2005, the SLR got dropped to $25 \%$ and CRR to $4.5 \%$ of total deposits. The reforms were however, more comprehensive and led to sharp changes in various parameters of banking system. Further, on the basis of the recommendations of the Steering Committee set up by RBI, 'Ownership and Governance' and the implementation of the 'New Capital Adequacy Framework' were formulated and issued to banks on February 15 , 2005. As a result, the restrictions on geographical expansion and ceiling on interest rates were removed. With increased competition, declining margins on current business

\footnotetext{
${ }^{2}$ The reforms were based on the recommendations of the Committee on Financial Systems (CFS) (Narasimham 1991) first, followed by those of Committee on Banking Sector Reforms (BSR) (Narasimham 1998) in a phased manner.
} 
operations, higher costs and greater risks, banking industry in general, had to face a two pronged challenge. They had on the one hand, to enhance their productivity and on the other, increase their ability to serve the nation in new ways with greater efficiency and effectiveness.

In such a scenario, banking industry had to sustain itself by increased reliance on cost minimization and by ensuring greater efficiency. Indian scheduled commercial banks in general, and the nationalized banks in particular, have had to spearhead the growth in banking business as they account for an overwhelming share of Rs 13,60,724 Crs' as total deposits and Rs 957697 Crs' as advances as on March, 2007. These reforms were broadly aimed to improve the performance of banks despite the unexpected global recession and internal disturbances. At this juncture banking sector is immensely competitive and growing in the right trend (Ram Mohan, 2008). With this in view it becomes necessary to ask weather the performance has improved? In what way and how much? The present study is thus focused on the following objectives:

- To review, problems related to the measurement of inputs and outputs.

- To measure productivity growth in Indian scheduled commercial banks (excluding Regional Rural Banks $R R B$ ) wherein, we identify productivity performance along with technical efficiency.

- To under take a comparison of efficiency gains across different groups of banks.

The exercise is based on the semi-parametric method of efficient estimation as proposed by Sickles (2005).

\section{Issues in the Measurement of input and Output}

Let us now turn to a review of empirical studies dealing with some broadly categorized aspect of the problem relating to the measurement of output. Obtaining a valid measure of output is crucial for modeling bank efficiency. In the literature, a variety of approaches have been followed and there is no harmony, among the researchers, on the measurement of banking output. The issue of measuring output assumes a special importance in the present case due to the fact that commercial banking is a service industry with all possible complications. First there is disagreement over which services are produced and how to measure them. Additionally, services in banking industry are often priced implicitly on the basis of below market interest rates on deposit balances, rendering observed revenue flow rather inaccurate as a measure of output. Second, banking also remains a highly regulated 
industry in which substantial inefficiencies have been shown to exist. As a result, technical improvements that increase the productivity of most efficient firms may not be well reflected in the industry as a whole. Despite these difficulties it becomes important to analyze the externalities that a bank generates through its roles as the primary financial intermediary and for conduct of monetary policy. There are mainly two approaches for the selection of inputs and outputs the production approach and intermediation approach. Both these approach apply tradition micro economic theory of firm to banking and differ in specification of banking activities. The available literature on the identification of inputs and outputs let to the establishment of asset, user cost and value added approach. All the three approaches are the variants of intermediation approach.

According to the production approach, a bank activity that absorbs real resources is bank output. Benston, et, al, (1982) observes that output is measured in terms of what banks in turn form the basis of operating expenses. In this approach, banks are viewed as producers of loans and deposits account services using available input. Under this approach, outputs are measured by the number of accounts services as opposed to the rupee value and cost, interest expenses are excluded. Berger and Humphrey (1992) define bank outputs as behavior, which have large expenditure on labour and capital, and they are included in the deposits as both outputs and inputs of banking.

Purchased funds (commercial deposits, foreign deposits, and other liabilities) are considered as financial inputs to the intermediation process, as they require very small amounts of physical inputs (labour and capital). On the asset side, government securities and other nonloan investments are considered to be unimportant outputs, because their value-added requirements arc very low. Again, the cost criterion followed in the production approach does not adequately serve to distinguish financial inputs from financial outputs. Since, obtaining any financial input incurs some labour and capital costs. According to Mamalakis (1987), these measures of output in banking do have serious conceptual and measurement problems ${ }^{3}$.

\footnotetext{
${ }^{3}$ Mamalakis (1987) attempted to solve the banking imputation problem, first, by developing and using a theory of financial Services. The gross Interest rate was unbundled into (a) the pure Interest rate. (b) charges for financial services and (c) other (unilateral transfer) charges. Second. It was demonstrated that the charges for financial services are totally separate and distinct from the property Income called (pure) interest. Third. It was shown that a "banking Imputation" equal to the difference between property income received and property Income paid out, as recommended the United Nation, overstates Income generated by the financial sector by an amount equal to reserves for future losses (estimated unilateral transfers).
} 
The user cost approach determines whether a financial product is an input or an output on the basis of its net contribution to bank revenue. If the financial returns on an asset exceed the opportunity cost of funds or if the financial costs of a liability are less than the opportunity cost, then the instrument is considered to be a financial output. Otherwise, it is considered to be a financial input Barman, (2007). Hancock, (1985) first applied the user cost approach. In a nutshell the user cost of a financial product can be calculated as its holding cost minus the reference rate. However, it is difficult to translate this concept into practice for several reasons Barman and Samanta, (2007). The complexities involved in measuring income begin with the initial conceptualization of a bank's output set, and persists with the issues involved in pricing various inputs and outputs. For example, is the service of accepting deposits an input or an output? What is the price paid by the depositor for indirect banking services such as safe custody and the issuance of cheques? And, as related questions; how are financial services sold? Are they number of transaction based or quantity of money based? The recognition and assessment of output and prices for these components of intermediation services present many challenges, both methodological and empirical.

Under the asset approach also called, intermediation approach, banks are financial intermediaries between liability holders and for those who receive bank funds. Sealey and Lindley (1977) consider loans and other assets as bank output, as they generate the bulk of the direct revenue that banks earn; deposits and other liabilities as inputs to the intermediation process because they provide the raw material of investible funds. Mamalakis (1987) makes some distinction between the funds intermediation and deposit services of a bank, whereas the asset approach considers only the former. Another criticism of this approach is that its grouping of inputs and outputs is arbitrary the choices made by some researchers are disputed by others, and the approach admits no mechanisms for resolving such debates ${ }^{4}$. Thus, the measurement of output of a bank remains a case of disagreement, among researchers. In this study, we specify earning assets, i.e., loans and investments are output. Following intermediation approach, we define output as the rupee value of total earning assets, say (Y). Since loans and investment generates the bulk of the revenue that banks earn, we use implicit GDP price deflators to obtain the real values of output.

4 Triplett (1991) Comment in Berger and Humphrey (1992) 


\section{Evaluation of Efficiency}

Studies on bank productivity and efficiency have mostly related to the United States. For India investigations of this nature are still in a nascent stage and have typically adopted two approaches. The parametric Stochastic Frontier Analysis (SFA) and the non parametric Data Envelopment Analysis have been widely used for measuring efficiency scores in India. But estimation of efficiency scores using semiparametric methodology has been scarce. More specifically, the measurement of efficiency and productivity in Indian banks started with studies like Tyagarajan (1975), Rangarajan and Mampilly (1972), and Subrahmanyam (1993). While they examined various issues relating to the performance of Indian banking, none of these have examined the efficiency of bank service. Again, most of the writers have till date preferred the intermediation approach for two reasons. First, because this approach measures outputs in currency terms (dollars, pounds and rupees) which are readily available. Second, this approach takes into account both operating expenses as well as interest expenses.

Subsequently, Agarwal (1991) and Subrahmanyam (1993) have analyzed the banking sector's productivity growth, but no attempt has been made to link growth performance to changes in the regulatory environment. In particular, no attempt has been made to capture the effects of policy- included changes in quasi-fixed factors on productivity growth within a regulated environment. Following a new insight into the problem has given rise to some path breaking works (Bhattacharya et, al., 1997; Das, 1997; Sarkar et al., 1998 and Rammohan, 2002, 2003, 2004) which have evaluated the overall technical, allocative and scale efficiency of Indian banks governed under different regulatory regimes. These studies, however, share two limitations, namely, (i) the sample period relates only to the pre-reform period and, (ii) use of non-parametric Data Envelopment Analysis (DEA) to estimate technical efficiency, based on the input - output variables ${ }^{5}$.

Breaking away from the specific features of studies mentioned above, several noteworthy studies like Kumbhakar and Sarkar, (2003, 2005); Shanmugham. \& Das, (2004); Das et al., (2005); Sensarma, (2005); and Mahesh and Bhide, (2008) have recently been undertaken to examine bank efficiency in the post liberalization period, using Parametric analysis. We need to note that the objectives of commercial banks, whether cost minimization and or profit

\footnotetext{
${ }^{5}$ See (Sathya, 2001) for a demonstration of the change in efficiency scores when inputs are changed.
} 
maximization are indeed different from the objectives of the central bank of a country. For this reason any specific work would be more comprehensive if it addressed itself to the impact on credit creation. Mahesh and Bhide, (2008) address the impact of reform on the ability of the commercial banks to extend credit using parametric Stochastic Frontier Analysis (SFA) ${ }^{6}$ method of estimation, but does not go beyond 2004 Other studies stop short of even that year. Hence the need for updating.

An overview of the studies taken up so far shows that thy either, use the parametric SFA, or a non parametric ${ }^{7} D E A$ model to estimate efficiency. Typically under parametric frontier estimation, the functional form with respect to a subset of the regressors i.e. the density of the errors is not fully known. To overcome this problem in estimation we attempt to use a Semi Parametric Estimators as proposed by '(Sickles 2005)', explained in detail subsequently. Data on inputs, outputs and other related variables for Indian scheduled commercial banks (excluding regional rural banks) for the period 1979- 2008 are obtained from Reserve Bank of India's research department publication: Statistical Tables Relating to Banks in India 1979 through 2008. Following the standard classification of RBI banks are grouped into four different groups: 1) The Nationalized Banks (NB). 2) The State Bank and its Associates $(S B \& A) .3)$ domestic private banks (PB). 4) Foreign Banks (FB).

\section{We use the following measures:}

Outpu : we consider a multiple output and input measures, which are in particular applicable to Indian Banking industry, and different researchers more or less agree with the view that earning assets, ie Loans, investments are two outputs, through which the bulk of bank revenue is earned. Following intermediation approach, we define out put as the rupee value of total loans and total investments at the end of the year.

Loanable Fund: Deposits and borrowings are treated as loanable fund input. Borrowings include both market borrowings and refinancing. Fund input is measured by the total rupee value of deposits plus borrowings at the end of the period. We use GDP at factor cost as price deflators to deflate the values of outputs and Lonable fund input.

\footnotetext{
${ }_{7}^{6}$ The study by Sensarma (2005) looks only at cost and profit efficiency.

${ }^{7}$ Non-parametric or distribution-free inferential statistical models pursue mathematical procedures for statistical hypothesis testing like linear programming and kernels which, unlike parametric models, make no assumptions about the probability distributions of the variables being assessed.
} 
Labour Input: We measure labour by no of employees which comprises of all the employees viz., officers and other employees i.e., clerks and sub staff.

Capital input: Capital input is a crucial input in the production process and it is the most complex of all the inputs to measure. Therefore, the cost of capital services is calculated as a sum total of (a) Value of owned assets at the end of each period multiplied by PLR of IDBI (Rental cost of owned assets) for calculating the opportunity cost of owned assets. (b) Rental cost for rented and leased assets. (C) Cost arising due to depreciation and repairs and maintenance of bank property.

\section{Analytical model}

Before we move on to explain the semi parametric estimation it is advisable that we state in brief the salient characteristics of the parametric and the non parametric models. A parametric model or finite-dimensional model is a family of distributions that can be described using a finite number of parameters. These parameters are usually collected together to form a single k-dimensional parameter vector $\phi=(\phi 1, \phi 2, \ldots \ldots . ., \phi \kappa)$. Parametric methods are also used to estimate the frontier with an explicit functional form. These types of frontier estimation methods fall under stochastic frontier estimation (SFE) techniques. An advantage of using the SFE method is that it can handle stochastic noise. However, the requirement of apriori (explicit) specification of the production function and assumption of distributions for the error term without regard to the theory are considered as shortcomings of SFE.

On the other hand a Non-parametric or distribution-free inferential statistical model pursues mathematical procedures for statistical hypothesis. Linear programming methods to construct piecewise surface over the data or kernels are used in the estimation of non parametric models. The data envelopment analysis (DEA) method is largely used as a non parametric tool in the literature. Unlike parametric models, no assumptions are made about the probability distributions of the variables being included. One problem with this particular method is that it has infinite number of solutions. Moreover, addition of an extra firm in a DEA cannot result in an increase in efficiency scores of the existing firms. It implies that there exists no correlation between the sample size and efficiency. In other words, scale efficiency does not figure in such analysis. Altogether, addition of an extra input or output in 
a DEA model cannot result in a reduction in the efficiency scores. The point to be noted here is that, if an investigator wished to make an industry look good, he /she could reduce the sample size and increase the inputs /outputs in order to increase the efficiency scores. Well, this leads to the miscalculations of measurement errors and other stochastic noise. Thus, we note that both SFE and DEA techniques which have so far been used for India have serious limitations. Hence the need to take up a superior alternative.

To this end, we note that a semi parametric model combines both parametric and nonparametric models, designed to provide robust point estimates for the parameters that describe the technology while assuring the smallest standard errors for slope parameters. In semiparametric models, the parameter has both a finite dimensional component and an infinite dimensional component (often a real-valued function defined on the real space). They are often used in situations where the fully nonparametric model may not perform well or when the researcher wants to use a parametric model but the functional form with respect to a subset of the regressors or the density of the errors is not known.

A semi parametric model allows the regressors to be correlated with the random effects (random effects are nuisance parameters i.e a parameter which is not of immediate interest but which must be accounted for in the identification and analysis of those parameters which are of interest. The classic example of a nuisance parameter is the variance, $\sigma^{2}$, of a normal distribution, when the mean, $\mu$, is of primary interest.). The semiparametric models explore the impacts of various correlation patterns among random effects and regressors and therefore robust. We make use of Park, Sickles, Simar (PSS) efficient estimators for our inference. While SFA and DEA yield time-variant affects estimates, in the sense that the characteristics of output depend explicitly on time, the semi parameter efficient estimator gives us timeinvariant effects, whose output does not depend explicitly on time. With these broad perspectives, the present study attempts to estimate bank efficiency relating the impact of reform on its ability.

\section{Semi Parametric Estimation (SPE)}

The revenue frontier panel model used in the present study in its linear form can be written as

$$
Y_{i t}=\alpha_{i}+X^{\prime}{ }_{i t} \beta+\varepsilon_{i t}
$$

Where $i=1, \ldots, N$ donates the observation and $\mathrm{t}=1, \ldots, T$ denotes time period 
Let $\mathrm{Y}_{\mathrm{i}}=\left(\mathrm{Y}_{\mathrm{i} 1}, \ldots, \mathrm{Y}_{\mathrm{iT}}\right)$ be a scalar of output variables of $\mathrm{N}$ firms and', $\mathrm{X}_{\mathrm{i}}=\left(\mathrm{X}_{\mathrm{i} 1}^{\prime}, \ldots, \mathrm{X}_{\mathrm{iT}}\right)^{\prime}$ is a vector of input variables of $\mathrm{N}$ firms. $\boldsymbol{\beta}$ is the unknown parameters to be estimated. , $\boldsymbol{\varepsilon}_{i t}$ is a composite Stochastic error term. A stochastic process is a collection of random variables $\left\{X_{t}, t \in T\right\}$ on the same probability space, indexed by an arbitrary index set say $T$. An empirical process is a stochastic process based on a random sample. For our case $X_{1}, \ldots, X_{n}$ of i.i.d. is a sample of random variables, where the index $t$ is allowed to vary over $T=\mathbb{R}$, the real line.

The model for $X_{\text {it }}$ is drawn from a probability measure $P$ Where $\left\{\boldsymbol{P}_{\beta, \eta}: X_{\mathbf{i t}} \in \mathbb{R}^{\mathbf{d}} ; \boldsymbol{\beta} \in \mathbb{R}^{\mathbf{d}}\right.$ and $\boldsymbol{\eta} \in \boldsymbol{h}\}$ where $\eta$ is the unknown density of the residual $\varepsilon_{i t}$. The model is based on assumptions concerning conditional independence and uses nonparametric estimators for the random effects and parametric assumptions (normality) on the distribution of the errors. The $\varepsilon_{\text {it }}$ are assumed to be independent identical normal random variables with zero mean and variance $\left(0, \sigma^{2}\right)$. The $\left(\alpha_{i}, x_{i}\right)^{\prime}$ s assumed to be iid random variables having unknown density $h$ $(\cdot, \cdot)$ on $\mathbb{R}^{1+\mathrm{dT}}$. The unknown density is specified in the derivations of the semiparametric efficient estimators using kernel smoothers. The support of the marginal density of $\alpha$ is assumed to be bounded above (or below), where, for example, the bound $\beta$ provides the upper level of the production frontier or the lower level of the cost frontier.

We consider cases in which $\varepsilon_{i t}$ 's and $\left(\alpha_{i}, x_{i}\right)$ 's are independent as well as cases in which certain dependency structures exist. This generic panel model is reinterpreted as a parametric stochastic panel production frontier model (Pitt and Lee, 1981; Schmidt and Sickles, 1984). Note that the parameter spaces for $\mathrm{h}$ are infinite dimensional while those for $\beta$, and $\sigma^{2}$ are of finite dimensional, the model (1) is semiparametric and designed to provide robust point estimates for the parameters that describe the technology while assuring the smallest standard errors for slope parameter estimates. The efficiency measurements we pursue are residual based and thus have properties that are leveraged on the properties of the slope parameters which are used in their construction. We use Mat Lab programming to arrive at the end results. The methodology of semi parametric estimation and the estimation of slope parameters as proposed by Sickles (2005) is briefly outlined in an appendix at the end of the paper. 


\section{Empirical Results:}

In this section we report three set of results. First, we take up investigations relating to output semiparametric frontier efficient estimates based on panel data which comprises of four cross sections viz., Nationalized Banks other than SBI and Associates (NB), State Bank and its Associates (SBI), Indian Private Banks (PB) and Foreign Banks (FB) for the period 1979 through 2008, giving us a total of 120 observations. This section also makes a comparison of relative technical efficiency scores at aggregate as well disaggregate levels for all the four groups of banks in the sample. Next we take up bench marking each group of banks relative to the frontier bank and thereby evaluate the output targets and input slacks. This gives us an idea of the extent to which the banks below the frontier can work out strategies for moving towards the best practices and thereby increase their efficiency. Finally, we turn to the vital question of total factor productivity growth.

\subsection{Aggregate Time-Invariant model}

Over the years, the two major issues that gained primacy in econometric analysis of Indian banks are technological progress and efficiency. Each of these could be a factor behind productivity and their respective roles in the Indian context which are worth investigating. Meanwhile, since for most of the banks the hypothesis of time variance is not supported by the data, we have estimated the time-invariant model for all the banks. On identifying the relevant variables, a multiple output semiparametric frontier efficient estimator is estimated in which random effects and the regressors have certain patterns of correlation. The efficient semi-parametric estimates allow for dependency between the random effects and long run movements in a subset of regressors.

Thus we relay on the efficient estimator of $\theta$ on a certain bandwidth (' $\mathrm{s}$ '), which is chosen by a bootstrap procedure. The bootstrap choice of " $\mathrm{s}$ " is $\mathrm{s}^{*}=\operatorname{argmin} \mathrm{C}(\mathrm{s})$. Where $\mathrm{C}(\mathrm{s})$ is given by:

$$
C(s)=(1 / M) \quad \sum_{m=1}^{M}\left[\hat{\theta}_{N, T}^{*(M)}(s)-\hat{\theta}_{N, T}(s)\right]\left[\hat{\theta}_{N, T}^{*(M)}(s)-\hat{\theta}_{N, T}(s)\right]
$$

Let $\mathrm{M}$ project the data into individual means, $\mathrm{T}$ represents Time period, $\mathrm{N}$ is the number of

cross section; NT is the no of observation, $\hat{\theta}_{N, T}^{*(M)}(s)$ denotes $\mathrm{M}^{\text {th }}$ pseudo sample bootstrap version of $\hat{\theta}_{N, T}(s)$ using bandwidth "s". The estimates consist of a grid search in the interval $[0.1,0.6]$. The optimal value of $\mathrm{s}^{*}$ is 0.5 on the pre selected panel data. The output from the 
Matlab programming is tabulated in Table- 1 . We use the Cobb Douglas functional specification, namely,

$$
\ln Y_{\mathrm{it}}=\alpha_{\mathrm{i}}+\beta_{1} \ln \boldsymbol{F}_{i t}+\beta_{2} \ln K_{i t}+\beta_{3} \ln L_{\mathrm{it}}+\varepsilon_{\text {it }} \text { where } i=1, \ldots, N ; \mathrm{t}=1, \ldots, T
$$

$\mathbf{Y}_{\mathrm{it}} \quad=$ is a scalar of multiple output, comprising Total Advance and Total Investment.

$\mathbf{F}_{\mathrm{it}} \quad=$ represents Lonable Fund input (Deposits and borrowings).

$\mathbf{K}_{\text {it }} \quad=$ correspond to Capital arrived through Perpetual Inventory Accumulation Method

$\mathbf{L}_{\mathrm{it}} \quad=$ stand for Labour (total no of employees).

$\varepsilon_{i t}=$ denotes the composite error term, which are assumed to be iid. $\mathrm{N}\left(0, \sigma^{2}\right)$.

Where ' $\mathbf{t}$ ' refers to time period, and ' $\mathbf{i}$ ' to the observation.

Table:1 Semi Parametric Park, Sickles, \& Simar Estimates for the Panel Data:

\begin{tabular}{|c|c|c|c|}
\hline (LnY):Dependent Variable & Elasticities & Standard Error & t - stat \\
\hline $\mathrm{C}$ & 0.057982 & 0.019317 & 3.00 \\
\hline$(\ln F)$ & 0.493574 & 0.022337 & 22.09 \\
\hline$(\ln K)$ & 0.428315 & 0.020149 & 21.25 \\
\hline$(\ln L)$ & 0.267718 & 0.005454 & 49.08 \\
\hline Adjusted R2 & \multicolumn{3}{|c|}{0.93} \\
\hline Returns to scale & \multicolumn{3}{|c|}{ 1.189607 } \\
\hline $\begin{array}{l}\text { Aggregate Mean efficiency } \\
\text { of Indian Scheduled } \\
\text { Commercial Banks }\end{array}$ & \multicolumn{3}{|c|}{0.832736} \\
\hline $\begin{array}{r}\text { Sample period (T)( } 1 \\
\text { Truncation for outliers }\end{array}$ & 979 to 2008$)$ & $\begin{array}{l}30 ; \mathbf{N}=4 ; \mathbf{N T}=1 \\
\text { earch in the intei }\end{array}$ & $\begin{array}{l}120 ; \mathbf{s}^{*}=0.5 ; \\
\text { rval = }[0.1,0.6] .\end{array}$ \\
\hline
\end{tabular}

Sources: Author's Calculations.

All the estimated coefficients are significant at one percent level of significance. Returns to scale are increasing, the goodness of fit is impressive and the elasticities of output with respect to fund input $(\mathrm{F})$, capital $(\mathrm{K})$ and labour $(\mathrm{L})$ at their mean levels are all fairly large. Moreover it can be inferred that on an average Indian scheduled commercial banks are 83 percent efficient in generating revenue relative to the best practicing bank in the sample.

Turning now to Annual average Technical Efficiency indices in Table-2 one can infer that in general the efficiency of the banking industry has improved with more stability in working, and generating bank revenue after liberalization in 1991-92. 
Table-2: Disaggregate Annual Technical Efficiency Scores

\begin{tabular}{|c|c|c|c|c|c|c|c|}
\hline YEAR & $S B I \& A$ & $F B$ & $P B$ & YEAR & $S B I \& A$ & $F B$ & $P B$ \\
\hline $1979-80$ & 0.76 & 0.765 & 0.562 & 1994-95 & 0.835 & 0.795 & 0.775 \\
\hline 1980-81 & 0.79 & 0.766 & 0.545 & 1995-96 & 0.844 & 0.791 & 0.776 \\
\hline 1981-82 & 0.79 & 0.762 & 0.559 & $1996-97$ & 0.847 & 0.79 & 0.771 \\
\hline 1982-83 & 0.762 & 0.762 & 0.669 & 1997-98 & 0.841 & 0.78 & 0.769 \\
\hline 1983-84 & 0.769 & 0.769 & 0.672 & 1998-99 & 0.838 & 0.799 & 0.746 \\
\hline 1984-85 & 0.782 & 0.772 & 0.684 & $1999-2000$ & 0.84 & 0.789 & 0.731 \\
\hline $1985-86$ & 0.777 & 0.778 & 0.706 & 2000-01 & 0.839 & 0.788 & 0.722 \\
\hline 1986-87 & 0.801 & 0.784 & 0.735 & 2001-02 & 0.842 & 0.778 & 0.723 \\
\hline 1987-88 & 0.819 & 0.765 & 0.724 & 2002-03 & 0.851 & 0.786 & 0.728 \\
\hline 1988-89 & 0.828 & 0.784 & 0.734 & 2003-04 & 0.845 & 0.786 & 0.726 \\
\hline $1989-90$ & 0.835 & 0.774 & 0.74 & 2004-05 & 0.852 & 0.782 & 0.722 \\
\hline $1990-91$ & 0.846 & 0.785 & 0.765 & 2005-06 & 0.86 & 0.789 & 0.704 \\
\hline 1991-92 & 0.849 & 0.784 & 0.764 & 2006-07 & 0.875 & 0.762 & 0.688 \\
\hline 1992-93 & 0.838 & 0.798 & 0.768 & 2007-08 & 0.897 & 0.771 & 0.679 \\
\hline 1993-94 & 0.836 & 0.793 & 0.776 & 2008-09 & 0.899 & 0.792 & 0.891 \\
\hline $\begin{array}{l}\text { Pre -Reform } \\
(1979 \text { - 1992) }\end{array}$ & 0.803 & 0.774 & 0.687 & \begin{tabular}{|c|} 
Post - \\
Reform \\
$(1993-$ \\
2008) \\
\end{tabular} & 0.853 & 0.786 & 0.745 \\
\hline \multicolumn{8}{|c|}{ Consolidated Average technical efficiency: 1979 through 2008.} \\
\hline \multicolumn{2}{|c|}{ NB } & \multicolumn{2}{|c|}{ SBI \&A } & \multicolumn{2}{|c|}{$\boldsymbol{F B}$} & \multicolumn{2}{|c|}{$P B$} \\
\hline \multicolumn{2}{|c|}{1.00} & \multicolumn{2}{|c|}{0.838} & \multicolumn{2}{|c|}{0.780} & \multicolumn{2}{|c|}{0.718233} \\
\hline \multicolumn{8}{|c|}{ Ranking } \\
\hline \multicolumn{2}{|l|}{1} & \multicolumn{2}{|c|}{2} & \multicolumn{2}{|c|}{3} & \multicolumn{2}{|c|}{4} \\
\hline
\end{tabular}

Sources: Author's Calculations.

Nationalised Banks (NB) being the frontier bank group on the most efficient belt, its relative Technical efficiency score is 1.00 for each year.

The public sector banks i.e. the nationalized banks and SBI and its associates are more efficient for generating substantial bank revenue compared to domestic private banks and foreign banks. Looking back we see that PSBs have been exposed to increasing competitive environment through entry of new private banks, relaxations on the entry of foreign banks, near total deregulation of the interest, the rate structure, increased functional autonomy and operational flexibility in a large number of areas for PSBs. Moreover, PSBs were the most controlled banks during pre- liberalization period and continue to be government controlled. Despite this they turn out to be the most efficient. This is rather amazing. 
Similar results are obtained by Sensarma 2005; Mohan and Ray (2004), Mahesh and Bhide (2008). One possible reason for the higher efficiency is due to the preference given by government itself and by public sector enterprises for their business, their branch network and long established presence. At the same time let us not forget the challenge that the Public sector banks face as they carry some of the burden of lending to the priority sector at subsidized interest rates. The new rule of no minimum balance due to financial inclusion also reduces the reserves, making the account levels fluctuate. In spite of these challenges this segment of banking industry has etched out a prominent place worth recognition and assimilation by other banks. The advance efficiency of SBI \& A shows a varying trend. It fluctuates between 80 and 83 percent. Our results show that foreign banks are considerably less efficient than PSBs this could be because of their relatively smaller scale. Since many of the regulations have now been relaxed these banks should perform better. For instance they are now allowed to have wholly owned subsidiaries, to open more branches, and to acquire domesticate private banks up to 74 percent. Thus, if they take advantage of this opportunity and expand their operations they can improve their efficiency levels bringing these on par with public sector banks.

The high level of efficiency of the foreign banks compared to the Domestic Private Banks is due to many factors: First, FBs became highly specialized in a few select areas, like, arranging foreign currency loans through loan syndications, investment banking, consultancy relating to investment activities, portfolio management, and in general capital market-related and derivative market-related services. Second, in retail banking they were confined to the elite clientele or high net worth customers. Wholesale banking had become the order of their style. Third, FBs offered their expertise to the Indian corporate sector to access foreign currency resources with the help of their overseas presence. Finaly, FBs had become highly mechanized and computerized, placing themselves a cut above the domestic banks in promoting banking services and products based on information and communication technology. All these factors have helped FBs to achieve a higher level of efficiency compared to domestic private banks. The latter were also handicapped particularly due to the entry of new private banks which were small in size. Moreover, the advance share of the old private banks declined in the post liberalization period. 
However, stagnation in the efficiency improvement after liberalization, rather than a turnaround in growth is also clear. The reasons being that after the liberalization, the banking industry had to cope with the challenge of a system that is increasingly being aligned to global norms of banking practices. Moreover commercial banks were not in a position to absorb the shock of liberalization, which had brought about a thorough change in their accounting norms, prudential regulations, free entry, and the scope of operation. The domestic private banks have done relatively worse when compared to other groups in the sample. This may perhaps be because of the fact that the latter three at the best of their capacity had adapted to the new environment more smoothly than the former. One may conclude that the policy environment would have created problems for the domestic private banks for reorganizing their operations for improvement of their dynamic efficiency.

\subsection{Bench Marking Targets Relative to Frontier Bank.}

Using the consolidated average technical efficiency scores computed '(see Table 2)', for the years 1979 through 2008; we arrive at the Input/output Mean and input /output targets in absolute terms. Since technical efficiency calculation is based on frontiers it explains how much of contraction of inputs is possible for the given level of output and alternatively how much expansion of output is possible for a given set of inputs. That is, a technically efficient frontier firm is the one which succeeds in converting a minimum set of inputs to maximum outputs. A firm that does this is considered to operate on the efficient frontier while the others operate below the frontier and their efficiency are correspondingly less. Ranking based on these scores reveal that the nationalized banks are the most technically efficient with efficiency scores of $100 \%$ from 1979 through 2008. The tabulated results are presented in the Table-3.

These calculations show that, if SBI\&A have to be as efficient as NB then it should produce same output using $16.3 \%$ less of currently used inputs, or maximize its output by $19.4 \%$ for the same level of inputs. At the same time if FB has to be as efficient as NB then it should produce same output using $21.6 \%$ less inputs, or increase its output by $27.6 \%$ for the same level of inputs. Similarly, PB to be efficient as NB then it should produce same output using 28.9\% less inputs, or increase its output by $40.8 \%$ for the same level of inputs. 
Table 3: Mean Input/Output and Input /Output Comparisons

\begin{tabular}{|l|l|l|c|c|}
\hline & $\begin{array}{c}\text { Nationalized } \\
\text { Banks } \\
\mathbf{( 1 0 0 \% )}\end{array}$ & $\begin{array}{c}\text { SBI and its } \\
\text { Associates (83.7\%) }\end{array}$ & $\begin{array}{c}\text { Foreign } \\
\text { banks } \\
\mathbf{7 8 . 3 6 \%}\end{array}$ & $\begin{array}{c}\text { Private } \\
\text { banks } \\
\mathbf{7 1 . 0 2 \%}\end{array}$ \\
\hline Mean output & $\mathbf{3 , 6 7 5 . 5 4}$ & $2,011.03$ & 450.86 & 991.72 \\
\hline $\begin{array}{l}\text { Mean Fund } \\
\text { Input }\end{array}$ & $\mathbf{3 6 6 , 5 3 6 . 8 0}$ & $185,556.25$ & 38194.16 & $106,076.93$ \\
\hline Mean Capital & $\mathbf{4 , 8 4 3 , 6 2 2 . 0}$ & $2,747,850.03$ & 703489.96 & $1,427,904$ \\
\hline Mean personal & $\mathbf{5 0 4 , 6 0 9 . 5 6}$ & $278,652.7$ & 13755.23 & $63,468.46$ \\
\hline \multicolumn{2}{|r|}{ Reduced Fund Input } & $155,310.58$ & 29928.94 & $75,335.83$ \\
\hline \multicolumn{2}{|r|}{ Reduced Capital } & $2,299,950.47$ & 551254.73 & $1,014,097.4$ \\
\hline \multicolumn{2}{|r|}{ Reduced personal } & $233,232.30$ & 10778.59 & 45075.30 \\
\hline \multicolumn{2}{|r|}{ Input slack percentage } & $16.3 \%$ & $21.64 \%$ & $28.98 \%$ \\
\hline \multicolumn{2}{|r|}{ Output target } & 2402.66 & 575.37 & 1396.39 \\
\hline \multicolumn{2}{|r|}{ Output slack percentage } & $19.4 \%$ & $27.61 \%$ & $40.80 \%$ \\
\hline
\end{tabular}

Sources: Author's Calculations.

Along the same lines, in absolute terms, this means that if SBI \&A were to operate on the efficient frontier it can achieve average revenue of 2,011.03 Crs with 83.7 percent of its current fund input, capital and personnel employed. That is the converse of an efficiency score of 83.7 percent, is the inefficiency of 16.3 percent $(100 \%-83.7)$ conveys that it can achieve the same output with 155,310.58 Crs of fund input as against 185,556.25 Crs and by using 2,299,950.47 Crs of capital instead of using 2,747,850.03 Crs also, by employing just 233,232.30 employees instead of 278,652.7.

If the third ranked FBs were to operate on the efficient frontier it can achieve average revenue of 450.86 Crs with 78.36 percent of its current fund input, capital and personnel employed. Thus an inefficiency amounting to 21.64 percent (100\% - 78.36\%) implies that FBs can achieve the same output with 29928.94 Crs of fund input as against 38194.16 Crs and by using 551254.73Crs’ of reduced capital instead of 703489.96 Crs also, by employing only 10778.59 employees instead of 13755.23. The fourth and last in ranking PBs were to operate on the efficient frontier it can achieve average revenue of 991.72Crs' with 71.02 percent of its present fund input, capital and personnel employed. An total inefficiency of 28.98 percent (100\% - 71.02\%) which implies that PBs can realize same output with 75,335.83 Crs of fund input as against 106,076.93 Crs and by using 1,014,097.4 Crs of reduced capital instead of $1,427,904$ Crs also, by employing only 45075.30 employees instead of $63,468.46$. 


\subsection{Total Factor Productivity Growth:}

Let us now finally look at the trend rates of TFPG for Indian scheduled commercial bank (excluding RRBs) estimated in keeping with growth accounting approach covering the span of study from1980-81 through 2008-09. In the equation below ' $\mathrm{Y}$ ' and ' $\mathrm{F}$ ' denote value of output and loanable fund input respectively. ' $L$ ' and ' $K$ ' denote labour employed and real capital stock. ' $w$ ' and 'n' are shares of wages and loanable fund in the output. Each variable is measured in log Scale. The weight of the capital input has been obtained as residual, i.e., by subtracting the sum of weights of labour and loanable fund inputs from unity.

$$
\begin{aligned}
& \ln \left(T F P_{t} / T F P_{t}\right)=\left[\ln \left(Y_{t} / Y_{t-1}\right)\right]-\left[\left\{w_{t}+w_{t-1}\right\} / 2 \ln \left(L_{t} / L_{t-1}\right)\right]-\left[\left\{n_{t}+n_{t-1}\right\} / 2 \ln \left(F_{t} / F_{t-1}\right)\right] \\
& -\left[\left\{\left(1-\left(w_{t}+n_{t}\right)\right)+\left(1-\left(w_{t-1}+n_{t-1}\right)\right)\right\} / 2 \ln \left(K_{t} / K_{t-1}\right)\right]
\end{aligned}
$$

In Table 4, TFPG is computed as the difference between the rate of growth of real output and the weighted rate of growth of factor inputs.

Table 4: Annual Total Factor Productivity Growth

\begin{tabular}{|l|l|l|l|}
\hline \hline year & $\begin{array}{c}\text { Total Factor Productivity } \\
\text { Growth (in \%) }\end{array}$ & year & $\begin{array}{c}\text { Total Factor Productivity } \\
\text { Growth (in \%) }\end{array}$ \\
\hline $\mathbf{1 9 8 0}$ & $\mathbf{0 . 8 2 4 0 5 3 8 4 1}$ & $\mathbf{1 9 9 5}$ & $\mathbf{0 . 8 3 9 6 4 8 2 9 3}$ \\
\hline 1981 & 1.022145719 & 1996 & 1.057940802 \\
\hline 1982 & 0.994377804 & 1997 & 1.285835004 \\
\hline 1983 & 1.035590165 & 1998 & 0.992401388 \\
\hline 1984 & 0.998191864 & 1999 & 1.02996028 \\
\hline 1985 & 0.995497086 & $\mathbf{2 0 0 0}$ & $\mathbf{0 . 8 1 5 7 0 6 8 6 1}$ \\
\hline 1986 & 1.02186672 & 2001 & 1.235481663 \\
\hline 1987 & 1.001930107 & 2002 & 1.144988166 \\
\hline $\mathbf{1 9 8 8}$ & $\mathbf{0 . 9 8 5 3 3 4 4 0 8}$ & 2003 & 1.196073221 \\
\hline $\mathbf{1 9 8 9}$ & $\mathbf{0 . 8 7 9 0 8 9 2 5 3}$ & 2004 & 1.003668478 \\
\hline $\mathbf{1 9 9 0}$ & $\mathbf{0 . 8 2 8 3 7 3 5 8 2}$ & 2005 & 1.016660749 \\
\hline $\mathbf{1 9 9 1}$ & $\mathbf{0 . 7 8 9 2 2 4 8 0 1}$ & 2006 & 0.998002816 \\
\hline 1992 & 1.138089289 & 2007 & 0.994557961 \\
\hline 1993 & 1.100412167 & & \\
\hline 1994 & 1.11924346 & 2008 & 1.054787222 \\
\hline \hline & Average TFPG & & $\mathbf{1 . 0 2 9 2 8 0 4 5 4}$ \\
\hline \hline
\end{tabular}

Sources: Author's Calculations.

A striking inference from the estimated growth rates is the declining trend from 1988 onwards with productivity growth going down to 79 percent in 1991. Despite undeniable and multifold gains of bank nationalization in $80 \mathrm{~s}$, it should be noted that the important financial institutions were then owned by state and they were subject to central direction and control. So banks had very little autonomy. Both lending and deposit rates were controlled until the 
end of the 1980s. Certainly, the nationalization helped in the spread of banking to the rural households and hither to uncovered areas. But, the monopoly granted to the public sector banks and lack of competition led to an overall inefficiency and low productivity. By 1991, the country's financial system was clearly saddled with an inefficient and financially unsound banking sector.

Later, however, the scenario changed substantially. As per the recommendation of the Narasimham Committee Report (1991), several reform measures were implemented which included the reduction of reserve requirements, de-regulation of interest rates, introduction of prudential norms, strengthening of bank supervision and improving the competitiveness of the system, particularly by allowing the entry of private sector banks. Up-gradation of technology, human resource development, etc., all helped in promoting the overall productivity growth in the banking sector 1991 onwards.

However the productivity that increased due to reforms shows a declining trend after 1998 collapsing to 81 percent by 2000. This is mainly due to of the sluggishness in the Indian economy during the initial years of liberalization due to which there was a lack of demand for bank credit from the industrial sector. A comprehensive policy framework for governance in private sector banks was put in place in February $2005^{8}$. A framework based on the recommendations of Ganguly Committee and a review by the Board for Financial Supervision (BFS) was meant to ensure that the ultimate ownership and control was well diversified; important shareholders, directors and CEO were working 'fit and proper' observing sound corporate governance principles. Private sector banks were said to maintain minimum capital for optimal operations and for systemic stability. Indeed the second generation reforms were effective and a turning point in productivity growth.

\section{Summary and conclusion}

The present study attempts to measure productivity and thereby efficiency of Indian scheduled commercial banks for the period 1979 through 2008 using the asset approach, under which bank output is measured as quantum of bank revenue (loans and investments). Technical efficiency measure has been examined, using semi parametric PSS efficient estimates. Our discussion has highlighted the consistency and empirical superiority of these

\footnotetext{
${ }^{8}$ Guidelines on corporate governance, RBI, June 20, 2002.
} 
estimates over the alternatives of non parametric and parametric approaches. Based on this methodology our results show that the banking system has gone through two major policy upheavals; nationalization in 1969 and deregulation and other reforms in mid nineties. Both of these have had a significant impact on the efficiency and productivity in the banking industry in two different ways. Significant changes in the policy environment have clearly enabled banks to expand their operations efficiently under the new liberalized atmosphere.

It turns out that the public sector banks (PSB) i.e. the nationalized banks (NB) and state bank of India and its associates (SBI\&A) are more efficient compared to domestic private banks and foreign banks. Rather surprisingly, foreign banks are considerably less efficient than PSBs possibly because of their relatively smaller scale. However, the foreign banks have higher efficiency compared to the domestic private banks, due to their specialized activities. In view of the fast changes taking place in the banking industry in response to the rapid growth of the real sector of the economy, the conclusions presented here should be viewed as only broadly indicative. 


\section{References}

Agarwal, R. N (1991)., "Productivity Growth and Economies of Scale in Public Sector Banks in India: 1969-1986.’’ Productivity 32, July-Sept..

Bhattacharya Arunava, Lovell, C.A. Knox, and P. Sahay (1997), The Impact of Liberalization on the Productive Efficiency of Indian Commercial Banks, European Journal of Operational Research, 98: 332.45.

Barman, R. B. and G. P. Samanta (2007):”Measuring Banking Intermediation Services, Issues and Challenges for India”, Economic and Political Weekly, 42 (15) pp. 3754 3763.

Barman R. B., (2007), “Determinants of Profitability of banks in India” in: V. Pandit, K. R. Shanmugam editors, "Theory, Measurement and Policy: Evolving Themes in Quantitative Economics” Academic Foundation, New Delhi. (2008).

Benston, G. J., Hanweck, G., and D. B Humphrey (1982), “Scale Economies in Banking: A Restructuring and Reassessment”, Journal of money credit and banking, 14 pp. 435456.

Berger, A. N and D. B, Humphrev (1992), Measurement and Efficiency issues in Commercial banking, in Griliches, Z, eds., Measurement Issues in Service Sectors, National Bureau of Economic Research, University of Chicago Press, Chicago, pp 245279.

Berger, A. N., Hanweck, G., and D. B, Humphrey (1987) Competitive viability in banking: Scale, Scope and product-mix Economies, Journal of Monetary Economics, 20, pp. 501-520.

Das Abhiman (1997), 'Technical, Allocative and Scale Efficiency of Public Sector Banks in India', Reserve Bank of India Occasional Papers, Special Issue, JuneSeptember, 18, pp 279-301.

Das Abhiman, Ashok Nag, Subhash C Ray (2005) Liberalisation, Ownership and Efficiency in Indian Banking A Nonparametric Analysis, Economic and Political Weekly 19, 1190-1197.

Hancock, Diana. (1985), “The Financial Firm: Production with Monetary and Nonmonetary Goods. Journal of Political Economy 93: pp 859-80.

Jadhav, N and D. Ajit (1996), "Role of banks in the Economic Development of India”, Prajnan, 25, (3-4), pp. 309-409.

Kumbhakar, S. C., \& Sarkar, S. (2003), Deregulation, ownership and productivity growth in the banking industry: Evidence from India. Journal of Money, Credit, and Banking, 35, pp 403-414.

Kumbhakar, S. C., \& Sarkar, S. (2005), Deregulation, ownership and efficiency change in Indian banking: An application of stochastic frontier analysis. In R. Ghosh, \& C. Neogi (Eds.), Theory and application of productivity and efficiency, econometric and DEA approach. India: Macmillan.

Mamalakis, M. J., (1987) , The Tratment of Interest and Financial intermediaries in the National Accounts: the Old Bundle verses the new Bundle approach, The Review Of Income And Wealth, 33, pp. 169-192.

Mahesh H. P, and Shashanka Bhide (2008), "Do Financial Sector reforms Make Commercial banks More Efficient? A parametric exploration of the Indian Case”, The Journal of Applied Economic research. 2. (4).Pp.416 -440.

Narasimham. M (1991), Report of the Committee on the Financial System', Reserve bank of India Mumbai.

Narasimham. M (1998), Report of the Committee on Banking Sector Reforms, Reserve bank of India Mumbai 
Park, B.U., Sickles, R.C., Simar, L., 2003. Semiparametric efficient estimation of AR1 panel data models. Journal of Econometrics 117, 279-309.

Pitt, M. M., and L. F Lee (1981), "The measurement and sources of technical inefficiency in Indonesian weaving industry," Journal of Development Economics, 9, pp. 43-64.

Ram Mohan, T T (2002), 'Deregulation and Performance of Public Sector Banks', Economic and Political Weekly, 37 (5), pp 393-97.

Ram Mohan, T T (2003), 'Long-Run Performance of Public and Private Sector Bank Stocks', Economic and Political Weekly, 38 (8) pp 785-88.

Ram Mohan, T T and S C Ray (2004), 'Comparing Performance of Public and Private Sector Banks: A Revenue Maximisation Efficiency Approach’, Economic and Political Weekly, 39 (12), pp 1271-76.

Ram Mohan, T T. (2008) "Is It Time to Open Up to Foreign Banks”, Economic and Political Weekly, 43 ( 28) pp. July 12 -14,

Rangarajan, C., and Mampilly, P. (1972), "Economies of scale in Indian banking", in: Technical Studies for Banking Commission Report, Reserve Bank of India, Bombay, pp. 244-268.

Sickles, Robin C., (2005), "Panel estimators and the identification of firm-specific efficiency levels in parametric, semiparametric and nonparametric settings" Journal of Econometrics, 126, (2) 305-334

Sarkar, J, S and S K Bhaumik (1998), 'Does Ownership Always Matter? Evidence from the Indian Banking Industry', Journal of Comparative Economics, 26, pp 262-81.

Sathya, M. (2001). "Efficiency of banks in a developing economy: the case of India”. In "Proceedings of Examining ten years of economic reforms in India", ANU, Canberra, Australia.

Schmidt, P., Sickles, R. C. (1984). Production frontiers and panel data. Journal of Business Economics Statistics 2:367-374.

Sensarma. R (2005), “Cost and profit Efficiency of Indian banks during 1986 -2003: A Stochastic Frontier Analysis”, Economic and political Weekly, 40 (12): 198 -209.

Sealey, C. W. and Lindley, J. T., (1977), Inputs, Outputs and a theory of production and cost at Depository Financial institutions, Jurnal of Finance, 32, pp. 1251-1266.

Shanmugam, K.R. and Das, A. (2004), Efficiency of Indian commercial banks during the reform period, Applied Financial Economics, 14, 681-686.

Subrahmanyam, Ganti, (1993), "Productivity Growth in India's Public Sector Banks: 1970-1989.’' Journal of Quantitative Economics. 9, (2) pp. 209-223.

Tyagarajan, M. (1975), "Expansion of commercial banking. An assessment", Economic and Political Weekly 10, 1819-1824. 


\section{Appendix ${ }^{9}$}

Estimation of the Slope Parameters as Proposed by Robin C. Sickles, ‘(Sickles 2005:308)’ In this section we review the principles used to derive a semiparametric efficient estimators for analyzing productive efficiency. The basic ideas are somewhat intuitive. Let (X, Y) stand for a model's generic observations on the exogenous and endogenous variables and let $P$ be the set of all possible joint distributions of (X, Y). In the semiparametric model there are parameters of interest (e.g., the slope parameters) and parameters that are of indirect interest and are referred to as nuisance parameters (e.g., the distribution of the effects in a panel frontier model). Partition the parameters of the model $(\phi)$ into those of interest $(\beta)$ and those referred to as nuisance parameters $(\eta)$. So that $\phi=\left(\beta^{\prime}, \eta^{\prime}\right)$ '.

Let $P_{0}$ be a regular parametric sub model (see Ibragimov and Has'minskii, 1981, Section $1.7)$ and the probability measure $P\left(=P_{(\beta 0, \eta 0)}\right)$ belong to it, and $\ell(X, Y, \beta, \eta)$ denote the $\log$ likelihood of an observation from $P_{(\beta, \eta)}$. Now let the scores with respect to the parameters of interest and the nuisance parameters be

$$
\ell_{\beta}(X, Y)=\partial \ell /\left.\partial \beta\right|_{\left(\beta_{o}, \eta_{o}\right)} \text { and } \ell_{\eta_{j}}(X, Y)=\partial \ell /\left.\partial \eta_{j}\right|_{\left(\beta_{o}, \eta_{o}\right)} \text {, respectively, }
$$

where $\eta=\left(\eta_{1, \ldots .} \eta_{k}\right)$ which defines the efficient score function as $\ell^{*}=\ell_{\beta}-\pi\left(\ell_{\beta} \mid\left[\ell_{\mu}\right]\right)$. The vector $\left[\ell_{\eta}\right]$ simply denotes the linear span (S) generated by $\left[\ell_{\eta_{J}}\right]_{J=1}^{K}$. , and $\pi(\ell \mid S)$ denotes the vector of projections of each component of $\ell$ onto the space S. in that case the scores with respect to the parameters of interest are projected onto the nuisance parameter tangent space and then the scores are purged of these projections to get the efficient scores. Thus, they are designed in a way to be orthogonal to information contained in set of nuisance parameters. Such an estimator of the parameters of interest is adaptively estimable (Pagan and Ullah, 1999, p. 218) in that it does not require knowledge of the nuisance parameters but is still efficient. The estimator of $\beta$ is called semiparametric efficient if it is asymptotically normal with mean $\beta$ and variance $N^{-1} I^{-1}(P ; \beta)$ where $\mathrm{I}(\mathrm{P} ; \beta)=E \ell^{*} \ell^{*}$ is the information matrix for the semiparametric estimator of $\beta$. The asymptotic distribution of the semiparametric

\footnotetext{
${ }^{9}$ This appendix is to highlight the methodology proposed and developed by Sickles, (2005), which we use for our case with slight modification stylized to our case.
} 
efficient panel estimator $\hat{\beta}_{N, T}$ is: $\sqrt{N T\left(\hat{\beta}_{N, T}-\beta\right)} \rightarrow N\left(0, I^{-1}(P ; \beta)\right)$. For a further readings on the method of finding $I(P ; \beta)$ is discussed in Bickel et al. (1993).

\section{Estimation of individual effects and the level of the frontier function}

Now given a semiparametric efficient estimator $\hat{\beta}_{N, T}$ it is natural to predict the individual efficiency effects $\alpha_{\mathrm{i}}$ by the within residuals $S_{i}\left(\hat{\beta}_{N, T}\right)$.

$$
\hat{\alpha}_{i}=\bar{S}_{i}\left(\hat{\beta}_{N, T}\right)
$$

With fixed T (Park et al. 1998) show that

$$
\hat{\alpha}_{i}-\alpha_{i}=O_{p}\left(N^{-1 / 2}\right) \text {. }
$$

With $\mathrm{T} \rightarrow \infty$ and $\mathrm{N}$ fixed or tending to infinity (Park et al. 1998) also show that

$$
\sqrt{T}\left(\hat{\alpha}_{i}-\alpha_{i}\right) \rightarrow N\left(0, \sigma^{2}\right)
$$

The relative technical inefficiency of the $i^{\text {th }}$ firm with respect to the $j^{\text {th }}$ firm is specified by the difference between efficiency effects $\left(\alpha_{i}-\alpha_{j}\right)$. This can be estimated by $\left(\hat{\alpha}_{i}-\hat{\alpha}_{j}\right)$ which has the asymptotic $N\left(0,2 \sigma^{2}\right)$ distribution when normalized by $\sqrt{T}$ under the same assumptions. The support of the Marginal distribution of the effects $\alpha_{i}$ is the upper (lower) boundary B.

A natural estimator of this quantity is

$$
\hat{\beta}=\max _{1 \leq i \leq N} \bar{S}_{i}\left(\hat{\beta}_{N, T}\right) .
$$

This fact was pointed out by econometricians like Greene (1980) and utilized by Schmidt and Sickles (1984) and Cornwell et al., (1990) in developments of their panel stochastic frontier estimators. Let $\alpha(N)=\max _{1 \leq i \leq N} \alpha_{i}$ Then under a set of mild regularity conditions as $\mathrm{T}$ $\rightarrow \infty$ the following can be proven:

1) For fixed $N, \quad \sqrt{T}(\hat{B}-\alpha(N))=O_{P}(1)$.

2) For Large $N, \quad \sqrt{T}(\hat{B}-\alpha(N))=O_{P}(\log N)$.

3) For Large $N, \alpha(N)-B=O_{P}\left(N^{-\frac{1}{\delta+1}}\right)$.

Here the choice $\delta$ determines the extent to which the marginal density of the effects has a certain non-negligible mass near the boundary point $\mathrm{B}$. When $\delta=0$ which would be the case 
where the density at the boundary stays away from zero (such as a shifted half-normal or exponential), then $\hat{B}-B=O_{P}\left(T^{-1 / 2} \log N+N^{-1}\right)$ if both $\mathrm{N}$ and $\mathrm{T}$ go to infinity.

\section{The (PSS) Semi Parametric Estimation (SPE):}

The models for which the SPE estimators have been derived / vary depending on how the basic model assumptions are modified to accommodate a particular issue of misspecification of the underlying efficiency model. The estimators we use in our study are based on the series of papers by Park and Simar (1994) and Park et al. (1998, 2003a, b) and are all based on principles discussed in the previous subsection. The interested reader can find the technical derivations of these estimators in these papers.

The derivations of the SPE estimators believe the random effects and all of the regressors are dependent and therefore we specify a joint distribution using kernel smoothers. With the joint distribution specified as $\mathrm{h}(\cdot, \cdot)$, PSS (1998) showed that the SPE efficiency estimator is the familiar "Within Efficiency Estimator" introduced by Schmidt and Sickles (1984). Implementation of this estimator (and its variants below) utilize kernel functions $\mathrm{K}$ with bandwidth parameter(s) $s_{N}$ which tend to zero at certain rates. When there is no correlation between the effects and the regressors then the within estimator is no longer semiparametric efficient. In this case the joint distribution of the effects and regressors is:

$$
h(\cdot, \cdot)=h_{1}(\alpha) h_{2}(X)
$$

The semiparametric efficient estimator for this pure random effects model is derived in Park and Simar (1994). When there is correlation between the effects and a subset of " $q$ " regressors $\mathrm{X}^{(2)}{ }_{\text {it }}$ where $\mathrm{X}=\left[\mathrm{X}^{(1)}, \mathrm{X}^{(2)}\right]$ then we can assume that $\alpha_{i}$ and $\mathrm{X}^{(1)}{ }_{\text {it }}$ are conditionally independent in which case the joint density of the effects and the regressors can be written as:

$$
h\left(\alpha, \mathrm{X}^{(1)}, \mathrm{X}^{(2)}\right)=h_{1}\left(\alpha, \mathrm{X}^{(2)}\right) h_{2}\left(\mathrm{X}^{(1)} \mid \mathrm{X}^{(2)}\right)
$$

A variant of this model is one in which the dependence between $\alpha$ and $\mathrm{X}^{(2)}$ is through long run levels of $\mathrm{X}^{(2)}$. In the stochastic frontier production function setting this sort of dependency between $\alpha$ and long run levels in $\mathrm{X}^{(2)}$, proxied by $\bar{X}^{(2)}$, may be a natural result of misapplication of technology accompanied by long run changes in factors which contribute to technology’s misapplication. Although one can allow for general dependencies between 
the effects and the regressors with which they are correlated, the semiparametric estimator that results is based on a $\left(T_{\mathrm{q}}+1\right)$-dimensional kernel estimator whose convergence rate (for fixed $T$ ) is quite slow unless both $T$ and $q$ are small. However, if the joint density of $\left(\alpha, \mathrm{X}^{(2)}\right)$ is restricted to be:

$$
h_{i}\left(\alpha, X^{(2)}\right)=h_{3}\left(\alpha, \bar{X}^{(2)} h_{4}\left(X^{(2)}\right)\right) \text {, }
$$

Then the dimensionality of the joint distribution is reduced to a $(q+1)-$ dimensional density. For cases in which $q$ is small this estimator will have relatively rapid convergence properties. The revenue frontier estimated in the present study is based on the following model 4 . We use purpose built mat lab programming to arrive at the results. 